\title{
Effectiveness of hydrotherapy as an adjunct treatment for the management of breast cancer related lymphoedema in women following breast cancer surgery: a systematic review
}

\author{
Eleanor Bills \\ University of South Australia, biler001@mymail.unisa.edu.au \\ Matthew Delsar \\ University of South Australia, delmb002@mymail.unisa.edu.au \\ Steven O'Donnell \\ University of South Australia, odosf001@mymail.unisa.edu.au \\ Alexandra Rice \\ University of South Australia, ricap003@mymail.unisa.edu.au \\ Cory Stone \\ University of South Australia, stocy007@mymail.unisa.edu.au \\ See next page for additional authors \\ Follow this and additional works at: https://nsuworks.nova.edu/ijahsp \\ Part of the Oncology Commons, Other Rehabilitation and Therapy Commons, Physical Therapy \\ Commons, and the Physiotherapy Commons
}

\section{Recommended Citation}

Bills E, Delsar M, O'Donnell S, Rice A, Stone C, Kumar S. Effectiveness of hydrotherapy as an adjunct treatment for the management of breast cancer related lymphoedema in women following breast cancer surgery: a systematic review. The Internet Journal of Allied Health Sciences and Practice. 2017 Jan 01;15(4), Article 12.

This Systematic Review is brought to you for free and open access by the College of Health Care Sciences at NSUWorks. It has been accepted for inclusion in Internet Journal of Allied Health Sciences and Practice by an authorized editor of NSUWorks. For more information, please contact nsuworks@nova.edu. 


\title{
Effectiveness of hydrotherapy as an adjunct treatment for the management of breast cancer related lymphoedema in women following breast cancer surgery: a systematic review
}

\begin{abstract}
Cancer is a leading cause of death and disability around the world. Of all cancers, breast cancer commonly ranks amongst the top three. Surgical intervention for breast cancer is common and a possible side effect of this is breast cancer related lymphoedema (BCRL). Women with breast cancer related lymphoedema commonly have regional limb swelling and pain, which can negatively impact mental and social well-being as well as upper limb function. Hydrotherapy is therapeutic modality which may be used as an adjunct to self-management strategies after the intensive phase of lymphoedema management. Yet despite its popularity, recent research has questioned its effectiveness in clinical practice.
\end{abstract}

Purpose: To determine the effectiveness of hydrotherapy as an adjunct treatment to usual care on arm volume and pain when compared with usual care alone for women with breast cancer related lymphoedema.

Method: A comprehensive search of eight electronic databases, including Medline, Embase, CINAHL, Scopus, Web of Science, AMED, The Cochrane Library and PEDro was completed. Studies of adult women with secondary upper limb lymphoedema following breast cancer surgery, which measured lymphoedema volume, pain, upper limb and QOL outcomes were included. Methodological quality was assessed using a modified CASP tool for randomised controlled trials. The NHMRC FORM methodology was utilised to synthesise the evidence and provide an overall grade of recommendation.

Results: Four randomised controlled trials and one controlled clinical trial were included in this systematic review. Critical appraisal of the included studies revealed overall methodological quality to be moderate. Hydrotherapy interventions duration varied between 8 to 12 weeks with some similarities between outcome measures assessed. Collectively, there is mixed evidence to support the positive impact of hydrotherapy as an adjunct treatment on reducing lymphoedema volume in the short-term and emerging evidence for upper limb function, pain and QOL.

Conclusion: A small number of studies have investigated the effect of hydrotherapy as an adjunct treatment in the breast cancer related lymphoedema population. Hydrotherapy could be considered as an adjunct treatment for women with breast cancer related lymphoedema, although the evidence base is mixed. Hydrotherapy may have positive physiological as well psychosocial impacts, as it is delivered in a group setting. However, the current literature base is limited by small sample size, lack of standardised exercise parameters, inadequate baseline characteristic assessment and limited long-term follow-up.

\section{Author Bio(s)}

Eleanor Bills Current final year student at the University of South Australia, Adelaide.

Matthew Delsar Current final year student at the University of South Australia, Adelaide.

Steven O'Donnell Current final year student at the University of South Australia, Adelaide. BNurs.

Alexandra Rice Current final year student at the University of South Australia, Adelaide.

Cory Stone Current final year student at the University of South Australia, Adelaide.

Saravana Kumar BAppSc (Physio), MPT (Manipulative and Sports), PhD, is a senior lecturer at the School of Health Sciences, Sansom Institute for Health Research, University of South Australia, Adelaide. He is a 
registered Physiotherapist in Australia.

Authors

Eleanor Bills, Matthew Delsar, Steven O'Donnell, Alexandra Rice, Cory Stone, and Saravana Kumar 


\title{
TIAHSP \\ The Internet Joưnal of Allied Health Sciences and Practice \\ Dedicated to allied health professional practice and education
}

Vol. 15 No. 4 ISSN 1540-580X

\section{Effectiveness of Hydrotherapy as an Adjunct Treatment for The Management of Breast Cancer Related Lymphoedema in Women Following Breast Cancer Surgery: A Systematic Review}

\author{
Eleanor Bills \\ Matthew Delsar \\ Steven O'Donnell \\ Alexandra Rice \\ Cory Stone \\ Saravana Kumar, BAppSc, PhD \\ University of South Australia
}

Australia

\begin{abstract}
Cancer is a leading cause of death and disability around the world. Of all cancers, breast cancer commonly ranks amongst the top three. Surgical intervention for breast cancer is common, and a possible side effect of this is breast cancer related lymphoedema (BCRL). Women with breast cancer related lymphoedema commonly have regional limb swelling and pain, which can negatively impact mental and social well-being as well as upper limb function. Hydrotherapy is therapeutic modality which may be used as an adjunct to self-management strategies after the intensive phase of lymphoedema management. Yet despite its popularity, recent research has questioned its effectiveness in clinical practice. Purpose: To determine the effectiveness of hydrotherapy as an adjunct treatment to usual care on arm volume and pain when compared with usual care alone for women with breast cancer related lymphoedema. Method: A comprehensive search of eight electronic databases, including Medline, Embase, CINAHL, Scopus, Web of Science, AMED, The Cochrane Library and PEDro was completed. Studies of adult women with secondary upper limb lymphoedema following breast cancer surgery, which measured lymphoedema volume, pain, upper limb function, and QOL outcomes were included. Methodological quality was assessed using a modified CASP tool for randomised controlled trials. The NHMRC FORM methodology was utilised to synthesise the evidence and provide an overall grade of recommendation. Results: Four randomised controlled trials and one controlled clinical trial were included in this systematic review. Critical appraisal of the included studies revealed overall methodological quality to be moderate. Hydrotherapy interventions duration varied between 8 to 12 weeks with some similarities between outcome measures assessed. Collectively, there is mixed evidence to support the positive impact of hydrotherapy as an adjunct treatment on reducing lymphoedema volume in the short-term and emerging evidence for upper limb function, pain and QOL. Conclusion: A small number of studies have investigated the effect of hydrotherapy as an adjunct treatment in the breast cancer related lymphoedema population. Hydrotherapy could be considered as an adjunct treatment for women with breast cancer related lymphoedema, although the evidence base is mixed. Hydrotherapy may have positive physiological as well psychosocial impacts, as it is delivered in a group setting. However, the current literature base is limited by small sample size, lack of standardised exercise parameters, inadequate baseline characteristic assessment, and limited long-term follow-up.
\end{abstract}

\section{BACKGROUND}

Breast cancer develops when abnormal cells in the breast grow in an uncontrolled manner. ${ }^{1}$ Within Australia, of all cancers, breast cancer is the third most commonly diagnosed cancer $(27.3 \%)$ in women with an estimated health care cost of $\$ 331$ million. ${ }^{1,2}$ With increasing focus on screening, early detection, and intervention, the current survival rate for women following breast cancer diagnosis is estimated at $90 \% .^{1}$ Management of breast cancer includes surgical intervention (removal of affected breast tissue and lymph nodes), which may be complemented by radiotherapy and chemotherapy. ${ }^{1} \mathrm{~A}$ common clinical issue 
following surgery affecting $20 \%$ of women is breast cancer-related lymphoedema (BCRL), also referred to as secondary lymphoedema. ${ }^{1,3} \mathrm{BCRL}$ is characterised by an accumulation of protein rich fluid in the interstitial space resulting from the removal of axillary lymph nodes and impaired lymph drainage, primarily localised to the upper limb..$^{1,4}$

Symptoms of BCRL vary but include regional limb swelling, sensations of heaviness, tightness, pain, and paraesthesia resulting in reduced limb function and negatively impacting mental and social well-being. ${ }^{3,5}$ Conservative management of BCRL involves intensive (therapist-led) and self-management phases, which incorporate education, skin care, compression therapy, manual lymphatic drainage and exercises. ${ }^{6}$ Surgical and other interventions such as low level laser therapy and pharmacological interventions are only utilised when conservative management fails. ${ }^{1}$ In recent times, hydrotherapy has been proposed as complementary to usual care for BCRL. The wide-ranging benefits of hydrotherapy in health care have been well documented. ${ }^{7}$ The principles underpinning hydrotherapy for BCRL are that buoyancy assists shoulder range of motion, the water viscosity facilitates muscular strengthening, and hydrostatic pressure stimulates lymphatic flow, direction of travel, and lymphoedema removal through pressure exerted on lymphatic vessels. ${ }^{8} \mathrm{An}$ intervention that underpins these hydrotherapeutic principles is the aqua lymphatic therapy (ALT) method. ${ }^{9}$ This method incorporates self-massage, exercise, and compression therapy with an emphasis on slow rhythmic movements and deep breathing. ${ }^{9}$

With improved survival rates following breast cancer, the focus of breast cancer management has shifted from mortality to morbidity and promoting activity, participation, and function, and it is in this context that hydrotherapy may have a role to play. The effectiveness of hydrotherapy for BCRL has been investigated in a recent systematic review by Yeung and Semciw, who concluded that hydrotherapy was not effective for BCRL.10 While this was a high quality systematic review, it has some limitations. Firstly, hydrotherapy was compared to standard care, and in clinical practice, hydrotherapy is rarely offered as a stand-alone intervention. Secondly, the search strategy did not include grey literature with searching limited to merely five databases until January 2017. Finally, the systematic review (Level II on National Health and Medical Research Council (NHMRC) Evidence Hierarchy) only included randomised controlled trials, despite the availability of a number of other studies which could contribute to the evidence base.

This systematic review addressed the limitations of the previous systematic review in a number of ways. The review investigated the effectiveness of hydrotherapy as an adjunct treatment for BCRL, which reflects what occurs in clinical practice and hence has immediate clinical relevance. The search was comprehensive with inclusion of a number of databases including grey literature, which resulted in identification of new research. Furthermore, this review has an explicit focus on the parameters of hydrotherapy and uses the NHMRC FORM framework to synthesise the results. ${ }^{11}$ Thus, the aim of our review was to evaluate the effectiveness of hydrotherapy as an adjunct to usual care on arm volume and pain when compared with usual care alone, specifically considering intervention parameters.

\section{METHODS}

This review protocol is registered with PROSPERO (registration number: CRD42017060403).

\section{Search Strategy}

This review was produced in accordance with the Preferred Reporting Items for Systematic Reviews and Meta- Analyses (PRISMA) statement. ${ }^{12}$ In April 2017, eight electronic databases were searched by two independent reviewers. Primary electronic databases searched included Medline, Embase, CINAHL, Scopus, Web of Science, Allied Health, and Complementary Medicine Database (AMED). Appendix 1 displays the search strategy used to search the Medline database. Secondary databases searched included The Cochrane Library and the Physiotherapy Evidence Database (PEDro). Only studies published in English were included. Reference lists of key studies identified via electronic database searches were canvassed to identify any additional seminal studies (Pearling). Grey literature was also searched including prominent organisational websites (e.g. Cancer Australia and the Australasian Lymphology Association). Table 1 outlines the framework used to construct the research question using the Population, Intervention, Comparator, and Outcome (PICO) format. The following experts in lymphoedema management were contacted to ensure comprehensive identification of all relevant studies: Asha Ketteridge from the Adelaide Lymphoedema Clinic and internationally recognised authorities Marie-Eve Letellier and Dorit Tidhar. Internet search engines (Google and Google Scholar) were utilised to identify literature not readily available or yet published in primary and secondary databases. 
Table 1: PICO Search Strategy

\begin{tabular}{|l|l|}
\hline & \multicolumn{1}{|c|}{ Definition } \\
\hline Population & Adult women with secondary upper limb lymphoedema following breast cancer surgery \\
\hline Intervention & Hydrotherapy as an adjunct to usual care for breast cancer related lymphoedema \\
\hline Comparator & Usual care for breast cancer related lymphoedema \\
\hline Outcome & Primary: Lymphoedema volume \& pain; Secondary: Upper limb function \& QOL \\
\hline
\end{tabular}

\section{Study Design}

All variations of primary and secondary research evidence were searched for within the literature. However, only randomised controlled trials (RCT) and controlled clinical trials (CCT) were included in this review.

\section{Population}

Studies were considered for inclusion if participants were adult women with secondary upper limb lymphoedema following breast cancer surgery and who had completed the intensive phase of lymphoedema management. They were also included if participants with BCRL had undergone additional treatment for breast cancer, including radiotherapy and chemotherapy. Study exclusion occurred if lymphoedema was not attributed to breast cancer surgery and if participants were still categorised in the acute post-surgical phase.

\section{Intervention}

Studies were considered for inclusion if hydrotherapy was utilised as an adjunct to usual care. Studies applying Aqua Lymphatic Therapy (ALT) and water-based exercises to complement usual care were also included. Studies were excluded if focused on spa therapy or scar management.

\section{Outcome Measures}

Primary outcomes of interest were pain and lymphoedema arm volume. Secondary outcomes of interest included Quality of Life (QOL) and upper limb function. Studies incorporating the following outcome measures were included in this review:

- Pain: Visual Analogue Scale (VAS), Numerical Rating Scale (NRS) or the McGill Pain Questionnaire Short Form (MPQSF).

- Lymphoedema arm volume: Volumetry (water displacement and circumferential measurement using tape measures), infrared laser perometry and electrical impedance spectroscopy.

- QOL: Functional Assessment of Cancer Therapy - Breast Cancer (FACT-B version 4) questionnaire, the Upper Limb Lymphoedema (ULL-27) questionnaire and the European Organisation of Research and Treatment of Cancer Quality of Life (EORTC QLQ-BR23) questionnaire.

- Upper limb function: Disabilities of the Arm, Shoulder, and Hand (DASH) questionnaire, upper limb range of movement (ROM) measured with a goniometer and grip strength measured with a dynamometer.

\section{Study Selection}

Two reviewers independently undertook the search of each database in order to ensure reliability and reproducibility. The results from each database were exported into the industry standard bibliographic software tool Endnote ${ }^{\mathrm{TM}}$ to manage and sort studies identified through database searches and to facilitate duplicate removal. The remaining studies were transferred to data management software for systematic reviews, Covidence ${ }^{\mathrm{TM}}$. Once a preliminary list of studies was formulated from the database searches, the title and abstract of the studies was considered in conjunction with the exclusion/inclusion criteria. The two reviewers independently screened the titles and abstracts to identify the studies to be included. Where the reviewers were unable to ascertain inclusion/exclusion status from the title and abstract alone, the full-text was reviewed. The final list of included and excluded studies was then independently verified and approved by an external reviewer who had expertise in the systematic review processes

\section{Risk of Bias}

The methodological quality of the included studies was independently assessed by all five reviewers using a modified Critical Appraisal Skills Program (CASP) Randomised Controlled Trials critical appraisal assessment tool. ${ }^{13}$ The eleven-part questionnaire was rated with "yes," "no," and "can't tell." Majority consensus determined the final rating of the study in question. The reviewers modified the CASP to give it a numerical score; "yes" $=2$, "can't tell" $=1$ and "no" $=0$. Studies could be awarded a minimum score of 0 and maximum score of 22. Additionally, due to the nature of the studies, question four was modified so that a full score could be obtained if the study personnel were blinded and question two was eliminated to account for the CCT.

(C) The Internet Journal of Allied Health Sciences and Practice, 2017 
Data extraction:

Customised data extraction forms were developed specifically for this systematic review. These forms contained key elements including study type, population, intervention, comparator, outcomes, and results/ statistics of studies identified as pertinent to the review question. All five reviewers independently extracted relevant information from the included studies to ensure reliability and consistency. A meta-analysis could not be undertaken due to general heterogeneity of the included studies and the extracted data.

\section{Data Synthesis}

The review team utilised the NHMRC FORM methodology to grade and provide a framework to synthesise the evidence from the literature. ${ }^{11}$ The NHMRC FORM methodology considers all evidence dimensions of all studies, which are used in the development of a specific recommendation. There are five key components: 1) quantity and quality of evidence, 2) consistency, 3) clinical impact. 4) generalizability, and 5) applicability to the Australian health-care setting. The applicability component was not used in this review, given the findings may be relevant to an international population. This framework allowed evidencebased recommendations for future research and clinical practice to be made.

\section{RESULTS}

\section{Search Results}

The search strategy generated 214 "hits," and following removal of duplicates and review of full-text versions, five studies were included in the review. One of the final five included studies was identified by Pearling. Figure 1 provides an overview of the literature selection process. Reasons for exclusion of potentially relevant articles include:

- Not a RCT or CCT design

- Intervention did not include hydrotherapy

- No primary outcome measures used

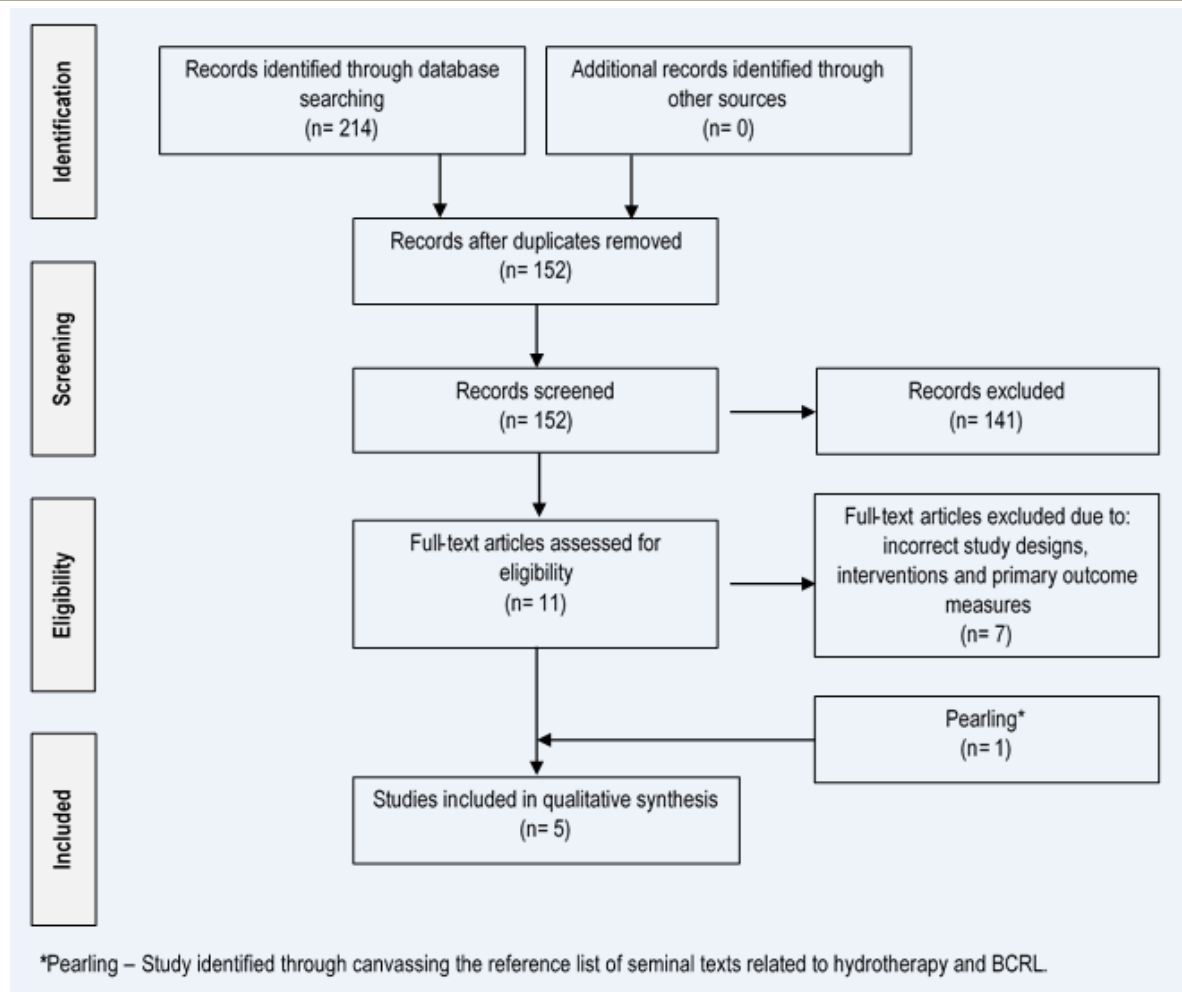

Figure 1: PRISMA Flowchart

\section{Ranking and Methodological Quality}

Ranking and methodological quality of the included studies were undertaken using the NHMRC evidence hierarchy and the modified CASP RCT critical appraisal assessment as seen in Table 2.13.14 According the NHMRC evidence hierarchy, four 
studies were classified as level II6,8,16,17 and one was classified as III-115. Common methodological flaws were attrition bias (not accounting for all study participants at the conclusion of the study), inconsistencies with similarity at baseline, and outcome measures considered. Two of the studies adequately accounted for all the participants by using an intention to treat analysis. 6,8 Only one study included all relevant biopsychosocial outcomes based on the inclusion criteria specified for this systematic review. ${ }^{8}$ One study that included baseline measurements had similarity between groups. ${ }^{16}$

\begin{tabular}{|c|c|c|c|c|c|}
\hline \multicolumn{6}{|c|}{ Table 2: CASP Scores } \\
\hline \multirow{2}{*}{$\begin{array}{l}\text { Modified Critical Appraisal Skills } \\
\text { Program (for Randomised } \\
\text { Controlled Trials) } \\
\text { Question Number }\end{array}$} & Hayes et al. ${ }^{17}$ & $\begin{array}{c}\text { Johansson } \\
\text { et al. }{ }^{16}\end{array}$ & $\begin{array}{l}\text { Letellier et } \\
\quad \text { al. }{ }^{8}\end{array}$ & $\begin{array}{c}\text { Tidhar \& } \\
\text { Katz-Leurer }{ }^{6}\end{array}$ & $\begin{array}{l}\text { Lindquist et } \\
\text { al. }{ }^{15}\end{array}$ \\
\hline & $\begin{array}{c}\text { RCT } \\
\text { (NHMRC II) }\end{array}$ & $\begin{array}{c}\text { RCT } \\
\text { (NHMRC II) }\end{array}$ & $\begin{array}{c}\text { RCT } \\
\text { (NHMRC II) }\end{array}$ & $\begin{array}{c}\text { RCT } \\
\text { (NHMRC II) }\end{array}$ & $\begin{array}{c}\text { CCT } \\
(\text { NHMRC III-1) }\end{array}$ \\
\hline $\begin{array}{l}\text { Q1: Did the trial address a clearly } \\
\text { focused issue? }\end{array}$ & 2 & 2 & 2 & 2 & 2 \\
\hline \multicolumn{6}{|l|}{$\begin{array}{l}\text { Q2: Was the assignment of patients } \\
\text { to treatments randomised? }\end{array}$} \\
\hline $\begin{array}{l}\text { Q3: Were all patients who entered } \\
\text { the trial properly accounted for at its } \\
\text { conclusion? }\end{array}$ & 0 & 0 & 2 & 2 & 0 \\
\hline $\begin{array}{l}\text { Q4: Were study personnel "blind" to } \\
\text { treatment? }\end{array}$ & 2 & 2 & 2 & 2 & 2 \\
\hline $\begin{array}{l}\text { Q5: Were the groups similar at the } \\
\text { start of the trial? }\end{array}$ & 1 & 2 & 0 & 0 & 0 \\
\hline $\begin{array}{l}\text { Q6: Aside from the experimental } \\
\text { intervention, were the groups treated } \\
\text { equally? }\end{array}$ & 2 & 2 & 2 & 2 & 2 \\
\hline \multicolumn{6}{|l|}{$\begin{array}{l}\text { Q7: How large was the treatment } \\
\text { effect?* }\end{array}$} \\
\hline \multicolumn{6}{|l|}{$\begin{array}{l}\text { Q8: How precise was the estimate of } \\
\text { the treatment effect?* }\end{array}$} \\
\hline $\begin{array}{l}\text { Q: Can the results be applied in your } \\
\text { context? }\end{array}$ & 2 & 2 & 2 & 2 & 2 \\
\hline $\begin{array}{l}\text { Q7: Were all clinically important } \\
\text { outcomes considered? }\end{array}$ & 0 & 0 & 2 & 0 & 0 \\
\hline $\begin{array}{l}\text { Q8: Are the benefits worth the harms } \\
\text { and costs? }\end{array}$ & 0 & 2 & 2 & 2 & 2 \\
\hline TOTAL SCORE /16 & 9 & 12 & 14 & 12 & 10 \\
\hline TOTAL SCORE IN \% (3sf) & $56.3 \%$ & $75 \%$ & $87.5 \%$ & $75 \%$ & $62.5 \%$ \\
\hline
\end{tabular}

Scoring: Yes $=2$, Can't Tell $=1$, No $=0{ }^{*}$ Questions $7 \& 8$ did not require a score to be allocated.

\section{Study Characteristics}

The characteristics of each study are outlined in Table 3. Publication dates of the included studies ranged from 2009 to 2017. They comprised of four single-blinded RCTs and one single-blinded CCT. The studies were conducted in Canada, Australia, Israel and two in Sweden. $6,8,15,16,17$ 
Table 3: Study Characteristics

\begin{tabular}{|c|c|c|c|c|c|}
\hline Study & Hayes et al. ${ }^{17}$ & Johannson et al. ${ }^{16}$ & Letellier et al. $^{8}$ & $\begin{array}{c}\text { Tidhar \& Katz- } \\
\text { Leurer }{ }^{6}\end{array}$ & Lindquist et al. ${ }^{15}$ \\
\hline Design & RCT & Pilot RCT & RCT & RCT & CCT \\
\hline $\mathrm{n}$ & 32 & 25 & 25 & 48 & 88 \\
\hline Population & No $R x=6 / 12$ & $\begin{array}{l}\text { Surgery } \geq 6 / 12 \\
\text { No } R x=3 / 12\end{array}$ & Surgery $\geq 6 / 12$ & $\begin{array}{l}\text { Intensive phase of } \\
\text { CPT } \geq 2 / 52\end{array}$ & $\begin{array}{l}\text { Completed CPT } \\
\text { intensive phase }\end{array}$ \\
\hline Intervention & $\begin{array}{l}\text { LBE \& hydro } 20 \\
\text { sessions x } 12 / 52\end{array}$ & $\begin{array}{l}\text { Hydro } 3 \times 30 \\
\text { min/week sessions } \\
\text { for } 8 / 52 \text {. } \\
\text { Self-management }\end{array}$ & $\begin{array}{l}\text { ALT } 60 \mathrm{~min} / \text { week for } \\
12 / 52 \\
\text { LBE } 25-30 \text { mins/day } \\
\text { Self-massage }\end{array}$ & $\begin{array}{l}\text { ALT } 45 \mathrm{~min} / \text { week for } \\
12 / 52 \\
\text { Self-management }\end{array}$ & $\begin{array}{l}\text { Hydro } 50 \\
\text { min/week for } \\
10 / 52\end{array}$ \\
\hline Comparator & $\begin{array}{l}\text { Usual habitual } \\
\text { activities }\end{array}$ & $\begin{array}{l}\text { Continue exercises } \\
\text { prior to study }\end{array}$ & $\begin{array}{l}\text { LBE } 25-30 \text { mins/day } \\
\text { Self-massage }\end{array}$ & Self-management & $\begin{array}{l}\text { LBE for } 10 / 52 \\
\text { Self-management }\end{array}$ \\
\hline Outcomes & $\begin{array}{l}\text { Lymphoedema vol. } \\
\text { - Bio-impedance } \\
\text { spectroscopy } \\
\text { - Perometry }\end{array}$ & $\begin{array}{l}\text { Lymphoedema vol. } \\
\text { - Bio-impedance } \\
\text { spectroscopy } \\
\text { - Perometry } \\
\text { - Water } \\
\text { displacement } \\
\text { UL Function } \\
\text { - Shoulder ROM }\end{array}$ & $\begin{array}{l}\text { Lymphoedema vol. } \\
\text { - Water } \\
\text { displacement } \\
\text { - Arm } \\
\text { circumference } \\
\text { Pain } \\
\text { - MPQ-SF } \\
\text { UL Function } \\
\text { - Upper extremity } \\
\text { function (DASH) } \\
\text { - Grip strength } \\
\text { (dynamometer) } \\
\text { QOL } \\
\text { - FACT-B version } 4\end{array}$ & $\begin{array}{l}\text { Lymphoedema vol. } \\
\text { - Water } \\
\text { displacement } \\
\text { QOL } \\
\text { - ULL-27 }\end{array}$ & $\begin{array}{l}\text { Lymphoedema } \\
\text { vol. } \\
\text { - Water } \\
\text { displacement } \\
\text { - Arm } \\
\text { circumference } \\
\text { UL Function } \\
\text { - DASH } \\
\text { - Shoulder ROM } \\
\text { QOL } \\
\text { - Body image: } \\
\text { Modified Likert } \\
\text { Scale } \\
\text { - Wellbeing: } \\
\text { Visual digital } \\
\text { Scale } \\
\end{array}$ \\
\hline Results & $\begin{array}{l}\text { Lymphoedema vol. * } \\
\text { - No significant } \\
\text { change }\end{array}$ & $\begin{array}{l}\text { Lymphoedema vol. } \\
\text { - No significant } \\
\text { change } \\
\text { UL Function* } \\
\text { - Flexion: } p \leq 0.001 \\
\text { - ER: } p=0.7 \\
\text { - Abduction: } p=0.32\end{array}$ & $\begin{array}{l}\text { Lymphoedema vol. }{ }^{* *} \\
\text { - } \text { vol.: } p=0.3 \\
\text { - circumference: } \\
p=0.12 \\
\text { Upper limb function }{ }^{* *} \\
\text { - Grip strength: } \\
\text { p }=0.008 \\
\text { - DASH: } p=0.016\end{array}$ & $\begin{array}{l}\text { Lymphoedema vol. } \\
\text { - Short-term }{ }^{* * *} \text { : } \\
\text { - } p<0.01) \\
\text { - Long-term: nil } \\
\text { QOL* } \\
\text { - Emotional: } p=0.03 \\
\text { - Social: } p=0.01 \\
\text { - Physical: } p=0.39\end{array}$ & $\begin{array}{l}\text { Lymphoedema } \\
\text { vol. } \\
\text { - } p=0.029^{*} \\
\text { - } p=0.046^{* *} \\
\text { UL Function } \\
\text { DASH } \\
\text { - } p=0.049 \\
\text { Shoulder ROM } \\
\text { - ER: } p=0.54 \\
\text { - Elevation: } \\
\quad p=0.014 \\
\text { (hydro) } \\
\text { - Abduction: } \\
\text { p=0.229 } \\
\text { QOL }{ }^{*} \\
\text { No significant } \\
\text { change }\end{array}$ \\
\hline Main Findings & $\begin{array}{l}\text { Hydro: Nil adverse } \\
\text { events }\end{array}$ & $\begin{array}{l}\text { Hydro: Improved } \\
\text { shoulder ER and } \\
\text { flexion }\end{array}$ & $\begin{array}{l}\text { ALT: Pain reduction } \\
p=0.04^{*}\end{array}$ & $\begin{array}{l}\text { ALT: Short-term } \\
\text { lymphoedema } \\
\text { improvement } \\
\text { Aspects QOL } \\
\text { improved }\end{array}$ & $\begin{array}{l}\text { Hydro: Reduction } \\
\text { in lymphoedema } \\
\text { volume }\end{array}$ \\
\hline
\end{tabular}

Key: *Intergroup comparison analysis, ${ }^{* *}$ Baseline-post intervention analysis, ${ }^{* * *}$ Change immediately post intervention, $\mathrm{n}=$ Number of Participants, $\mathrm{Rx}=$ Treatment, ALT = Aqua Lymphatic Therapy, $\mathrm{CPT}=$ Complex Physical Therapy, Hydro $=$ Hydrotherapy, LBE = Land Based Exercise, UL = Upper Limb, Mins = Minutes, ER = External Rotation, Vol. = Volume, ROM = Range of Movement, ULL-27 = Upper Limb Lymphoedema Questionnaire, FACT-B version $4=$ Functional Assessment of Cancer Therapy - Breast Cancer,

DASH = Disabilities of the Arm, Shoulder and Hand Questionnaire, MPQ-SF = McGill Pain Questionnaire Short Form. 


\section{Participant Characteristics}

The number of participants in the studies were $48,25,32$, and $88,6,8,15,16$ All participants were women who had undergone lymph node removal for breast cancer and experienced secondary lymphoedema as a result. One study included both upper limb and lower limb lymphedema; however, for the purpose of this review, only the upper limb results were considered. ${ }^{15} \mathrm{All}$ studies required participants to have completed the intensive phase of CDT. In three studies, women were a minimum of six months post-surgery.8,16,17 Participants in the study by Tidhar \& Katz-Leurer were on average between five to five and a half months upon statistical comparison, and in the study by Lindquist et al., participants were on average eight years post breast cancer treatment. 6,15

\section{Types of Intervention}

Four of the five studies reviewed were supervised by physiotherapists. The participants in the unsupervised sessions received instructions on how to perform the exercise program. ${ }^{16}$ The "ALT method" was utilised as the foundation for the intervention of two studies.6,8,9 In adjunct to "ALT method," Letellier et al. incorporated the "Fluid motion- Exercises for Lymphoedema" DVD, which included a number of land-based remedial exercises and lymphedema therapy in the section for arm-related lymphedema. ${ }^{8}$ Both Hayes et al. and Lindquist et al. designed a hydrotherapy program that incorporated generalised strength and aerobic exercises, with Lindquist et al. additionally including active and passive stretching. ${ }^{15,17}$ Comparatively, Johannson et al. combined aerobic and specific shoulder ROM exercises. ${ }^{16}$ Intervention duration ranged from 8 to 12 weeks with three studies conducted for 12 weeks, one for 10 weeks, and the other 8 weeks. ${ }^{6,8,15}$-17 Three studies required participants to complete the intervention once weekly with sessions lasting 45 minutes, 50 minutes and 60 minutes. $6,8,15$ One study required participants to undergo three weekly sessions with a duration of 30 minutes $^{16}$. Additionally, one study had a total of 20 sessions over a 12week period with a progressive increase of duration from 20 to 30 minutes in the first week to $45+$ minutes in the final week. ${ }^{17}$ In two studies compression garments were worn 8,15 , in one it was optional ${ }^{17}$ and in two it was not a requirement $6,8,15-17$. Three studies reported on pool temperature, with the studies using the ALT method ranging from $31^{\circ}$ to $33^{\circ} \mathrm{C} 6,8$ and Lindquist et al. utilising a pool temperature of $28^{\circ}$ to $29^{\circ} \mathrm{C} .6,8,15$ Table 4 provides an overview of the intervention parameters.

\section{Outcomes}

Table 5 summarises the results of limb volume, pain, QOL, and upper limb function for the respective studies.

\section{Primary Outcomes}

\section{Limb Volume}

All studies investigated the effect of hydrotherapy on upper limb volume. Water displacement and circumferential measures were taken in three, while bioimpedence spectroscopy and perometry were measures reported in two studies. ${ }^{6,8,15-17}$ Tidhar \& Katz-Leurer and Lindquist et al. reported significant reduction $(p<0.01 ; p=0.029)$ in limb volume immediately following hydrotherapy. 6,15 There was no significant difference in reduction of arm lymphoedema volume between groups in the study by Lindquist et al.; however, a higher proportion of participants in the hydrotherapy group experienced reduced lymphoedema arm volume following the intervention. ${ }^{15}$

Pain

Letellier et al. was the only study to examine pain as an outcome, using the MPQ-SF. ${ }^{8}$ They found that following ALT, there was a significant reduction in pain $(p=0.04)$ with a moderate effect size of -0.7 .

\section{Secondary Outcomes}

Quality of Life

Quality of life was investigated in two studies.8,9 Letellier et al. found that there was a significant improvement in QOL within the ALT group $(p=0.021) .{ }^{8}$ However, compared to the control group, which undertook a land-based exercise and self-massage program, there was no significant difference between groups. Tidhar and Katz-Leurer used the ULL-27 Questionnaire and reported significant improvement in the emotional and social dimensions $(p=0.03 ; p=0.01) .{ }^{6}$ However, they did not find improvement in the physical dimension component.

\section{Upper Limb Function}

Three studies investigated the benefit of hydrotherapy for upper limb function. Lindquist et al. found that there was no significant benefit in shoulder range of motion following hydrotherapy, despite improvement in each domain. ${ }^{15}$ Additionally, the hydrotherapy group demonstrated no improvement in DASH scores. Johannson et al. identified that improvements in shoulder flexion and external rotation were significant $(p \leq 0.001 ; p=0.07)$, but abduction was not. ${ }^{16}$ Letellier et al. identified significant

(c) The Internet Journal of Allied Health Sciences and Practice, 2017 
improvements in both the control and intervention groups in affected side grip strength from baseline measures to postintervention $(p=0.008) .{ }^{8}$ There was no statistically significant difference between the groups following intervention.

\begin{tabular}{|c|c|c|c|c|c|c|}
\hline \multirow{2}{*}{ Study } & \multirow{2}{*}{ Summary } & \multirow{2}{*}{$\begin{array}{l}\text { Supervision } \\
\text { (Y/N) }\end{array}$} & \multirow{2}{*}{ Intensity } & \multirow{2}{*}{$\begin{array}{l}\text { Frequencyl } \\
\text { week }\end{array}$} & \multicolumn{2}{|c|}{ Duration } \\
\hline & & & & & Time (min) & Weeks \\
\hline Hayes et al. ${ }^{17}$ & $\begin{array}{l}\text { Weeks 1-2: } \\
\text { - FBE (aerobic) } \\
\text { Weeks 3-4: } \\
\text { - FBE (aerobic) } \\
\text { - Hydro (aerobic) } \\
\text { - Hydro (resistance) } \\
\text { Weeks 5-8: } \\
\text { - Aerobic (mixed) } \\
\text { - Hydro (resistance) } \\
\text { - FWE (land) } \\
\text { Weeks 9-12: } \\
\text { - Aerobic (mixed) } \\
\text { - MRE (land) } \\
\text { Compression garments } \\
\text { optional }\end{array}$ & $Y^{*}$ & $\begin{array}{l}\text { Weeks 1-4: } \\
\text { - Aerobic: Low-mod } \\
\text { (RPE: 3-5) } \\
\text { - Strengthening: Low } \\
\text { (20 reps/ex) } \\
\text { Weeks 5-8: } \\
\text { - Aerobic: Mod } \\
\text { (RPE: 4-6) } \\
\text { - Strengthening: Mod } \\
\text { (15 reps/ex) } \\
\text { Weeks 9-12: } \\
\text { - Aerobic: Mod-high } \\
\text { (RPE: 4-7) } \\
\text { - Strengthening: Mod- } \\
\text { high (10 reps/ex) }\end{array}$ & $\begin{array}{l}\text { Weeks 1-4: } \\
3 \\
\text { Weeks 5-8: } \\
4 \\
\text { Weeks 9- } \\
12: \geq 4\end{array}$ & $\begin{array}{l}\text { Weeks 1-4: } \\
20-30 \\
\text { Weeks 5-8: } \\
30-45 \\
\\
\text { Weeks 9- } \\
\text { 12: } \\
45+\end{array}$ & 12 \\
\hline $\begin{array}{l}\text { Johannson } \\
\text { et al. }{ }^{16}\end{array}$ & $\begin{array}{l}\text { Swimming + shoulder ex. } \\
\text { (performed with shoulder } \\
\text { immersed) } \\
6 \text { exercises, } 10 \text { reps }\end{array}$ & $\mathrm{N}$ & Mod (RPE: 11-13) & 3 & 30 & 8 \\
\hline $\begin{array}{l}\text { Letellier et } \\
\text { al. }{ }^{8}\end{array}$ & $\begin{array}{l}\text { 1. ALT method (Tidhar, } \\
\text { Shimony \& Drouin 2004): } \\
\text { - DB } \\
\text { - Proximal and distal UL } \\
\text { movements } \\
\text { - Massage } \\
\text { Compression garments (20- } \\
\text { 30mmHg) } \\
\text { Pool Temp: } 31-33 \text { C } \\
\text { 2. SM ("fluid motion DVD) } \\
\text { - Self-massage } \\
\text { - ROM/corrective } \\
\text { - Strengthening exercises }\end{array}$ & $\bar{Y}$ & $\begin{array}{l}\text { Low } \\
\text { Emphasis on slow } \\
\text { rhythmic movements + } \\
\text { DB }\end{array}$ & $\begin{array}{l}\text { ALT: } 1 \\
\text { SM: } \geq 6\end{array}$ & $\begin{array}{l}\text { ALT: } 60 \\
\text { SM: } 25-30\end{array}$ & $\begin{array}{l}\text { ALT: } 12 \\
\text { SM: } 12\end{array}$ \\
\hline $\begin{array}{l}\text { Tidhar \& } \\
\text { Katz-Leurer } 6\end{array}$ & $\begin{array}{l}\text { ALT method (Refer to } \\
\text { Letellier et al. (2014) above } \\
\text { Pool Temp: } 32-33 \text { C }\end{array}$ & $\mathrm{Y}$ & $\begin{array}{l}\text { Low } \\
\text { Emphasis on slow } \\
\text { rhythmic movements + } \\
\text { DB }\end{array}$ & 1 & 45 & 12 \\
\hline $\begin{array}{l}\text { Lindquist et } \\
\text { al. }{ }^{15}\end{array}$ & $\begin{array}{l}\text { Hydro: } \\
\text { - Strength, mobility \& } \\
\text { aerobic exercise } \\
\text { - Hold/relax exercises of } \\
\text { affected limb \& DB. } \\
\text { Compression garments } \\
\text { Pool Temp: } 28 \text {-29 C }\end{array}$ & $Y$ & Mod & 1 & 50 & 10 \\
\hline
\end{tabular}

Key: FBE $=$ Floor Based Exercise, Hydro $=$ Hydrotherapy, FWE $=$ Free Weight Exercise, MRE $=$ Machine-weight Resistance Exercise,

Mod $=$ Moderate, RPE $=$ Rate of Perceived Exertion, DB = Deep Breathing, ALT $=$ Aqua Lymphatic Therapy, SM = SelfManagement, Temp $=$ Temperature, $Y=$ Yes, $N=$ No, ${ }^{*}=$ some supervision provided. 
Table 5: Summary of Results

\begin{tabular}{|l|l|l|l|l|}
\hline \multirow{2}{*}{ Study } & Primary Outcomes & \multicolumn{2}{l|}{ Secondary Outcomes } \\
\cline { 2 - 5 } & Pain & $\begin{array}{l}\text { Lymphoedema } \\
\text { Volume }\end{array}$ & QOL & $\begin{array}{l}\text { Upper Limb } \\
\text { Function }\end{array}$ \\
\hline Hayes et al..$^{17}$ & NR & ND & NR & NR \\
\hline Johannson et al. ${ }^{16}$ & NR & ND & NR & $\uparrow^{*}+$ \\
\hline Letellier et al. ${ }^{8}$ & $\downarrow^{*}+$ & $\downarrow+$ & $\uparrow+$ & $\uparrow_{+}$ \\
\hline Tidhar \& Katz-Leurer ${ }^{6}$ & NR & $\downarrow^{*}+$ & $\uparrow^{*}+$ & NR \\
\hline Lindquist et al..$^{15}$ & NR & $\downarrow_{+}$ & NR & $\uparrow+$ \\
\hline
\end{tabular}

Key:

$\mathrm{NR}=$ No results (for this outcome measure in this study)

$\mathrm{ND}=$ No difference (between intervention and control)

* $=$ Results are statistically significant $(P<0.05)$

$\downarrow=$ Reduction with intervention

$+=$ Results are positive for intervention

$\uparrow=$ Increase with intervention

- = Results are not positive for intervention

\section{NHMRC Body of Evidence Framework}

Table 6 synthesises the results of the included studies using the NHMRC FORM framework. The included studies, despite being ranked as high level evidence, could only be considered as moderate quality due to methodological concerns. Furthermore, the evidence base is mixed due to variability in terms of outcome measures, baseline characteristics, differing intervention programs and a lack of long term follow-up; care should be taken when considering clinical application of hydrotherapy for BCRL. Therefore, there is mixed evidence to support the use of hydrotherapy as an adjunct treatment to usual care in BCRL and care should be taken in its application.

Table 6: NHMRC Body of Evidence Framework

\begin{tabular}{|c|c|c|}
\hline Component & Grade & Comments \\
\hline Evidence base & $\begin{array}{l}\text { B - Good } \\
\text { one or two level II studies with a low risk } \\
\text { of bias }\end{array}$ & $\begin{array}{l}\text { Quantity: total of five studies } \\
\text { Level II: four studies } \\
\text { Level III-1: one study } \\
\text { Quality: Moderate }\end{array}$ \\
\hline Consistency & $\begin{array}{l}\text { C - Satisfactory } \\
\text { Some inconsistency reflecting genuine } \\
\text { uncertainty around clinical question }\end{array}$ & $\begin{array}{l}\text { Consistent study design except one } \\
\text { Not all studies had baseline statistical comparisons } \\
\text { Although baseline data was available, not all potential cofounding } \\
\text { variables were considered (socio-economic status) } \\
\text { Large variety of outcome measures }\end{array}$ \\
\hline Clinical impact & $\begin{array}{l}\mathrm{C} \text { - Satisfactory } \\
\text { Moderate }\end{array}$ & $\begin{array}{l}\text { All intervention protocols were well described, one study did not } \\
\text { describe the control } \\
\text { Findings were mostly consistent for outcomes except for } \\
\text { lymphoedema volume } \\
\text { Only one study investigated pain as an outcome } \\
\text { No adverse effects were reported, however, reasons for dropouts were } \\
\text { not always disclosed } \\
\text { No studies had follow up }\end{array}$ \\
\hline Generalisability & $\begin{array}{l}\text { B - Good } \\
\text { Population studied in the body of } \\
\text { evidence are similar to the target } \\
\text { population for the guideline }\end{array}$ & $\begin{array}{l}\text { Population included is consistent with target population } \\
\text { Studies conducted in four different countries that have different ethnic, } \\
\text { religious and cultural beliefs } \\
\text { Participants were recruited from previous clinical trials and } \\
\text { lymphoedema health services } \\
\text { Two studies conducted power calculations, only one met the criteria. } \\
\text { Most studies had relatively small sample sizes. }\end{array}$ \\
\hline $\begin{array}{l}\text { Grade of } \\
\text { Recommendation }\end{array}$ & $\begin{array}{l}\text { C-Body of evidence provides some } \\
\text { support for recommendation(s) but care } \\
\text { should be taken in its application }\end{array}$ & $\begin{array}{l}\text { The studies were of moderate quality. } \\
\text { The current evidence base is mixed with discrepancies in outcome } \\
\text { measures, baseline characteristics, differing intervention programs and } \\
\text { a lack of long term follow-up. }\end{array}$ \\
\hline
\end{tabular}




\section{DISCUSSION}

The aim of this systematic review was to determine the effectiveness of hydrotherapy as an adjunct treatment for the management of upper limb BCRL. Despite the scarce evidence base, the included studies were of moderate methodological quality, with the majority being RCTs. Collectively, there is mixed evidence to support the positive impact of hydrotherapy on reducing lymphoedema volume in the short-term and emerging evidence for upper limb function, pain, and QOL. This finding is contrary to a recently published systematic review and meta-analysis on a similar topic which concluded that there is no benefit of hydrotherapy over standard land-based care. ${ }^{10}$

There are a number of reasons this conflicting finding. First, Yeung and Semciw investigated hydrotherapy as a replacement treatment to usual care, whereas this review has focused on it as a complement to usual care. ${ }^{10}$ We considered hydrotherapy as a complement to usual care as this reflects what occurs in routine clinical practice. In clinical practice settings, hydrotherapy is likely to be used as one of a package of treatments and not as a stand-alone treatment. Therefore, hydrotherapy is commonly used as an adjunct to other treatments. Second this systematic review included an additional study, which was not considered by Yeung and Semciw. ${ }^{10,15}$ This addition may have altered the evidence base. Finally, while Yeung and Semciw undertook a meta-analysis, this systematic review utilised a different framework (NHMRC FORM guide) to synthesis the evidence base. ${ }^{10}$ Unlike a meta-analysis, which reports on combined effect size, the NHMRC FROM guide considers a range of different evidence constructs when framing a recommendation.

\section{Type and Intensity}

Evidence from a doctoral research study suggests that slow, rhythmical movements incorporated into exercise programs with massage and deep breathing, as in the case of ALT, was the most effective method for reducing lymphoedema in the shortterm compared to other lymphoedema management. ${ }^{18}$ This is consistent with the findings of this review, with the two studies that used ALT reporting improvements in lymphoedema volume. ${ }^{6,8} \mathrm{~A}$ possible explanation for the effectiveness of this method includes slowly increasing pressure to shift lymph, creating a "pumping" response from frequent rest breaks dispersed within exercise and lymphatic stimulation through massage, as proposed by Williams. ${ }^{19}$ According to Beursken et al., ROM and strengthening exercises are an essential component in the improvement of upper limb function in a land-based setting. ${ }^{20}$ This is consistent with this review's findings, where all studies that investigated upper limb function had positive improvements. The three studies all incorporated different exercises to target upper limb function, and consequently, although it appears to be an integral element, the type, intensity, and how they are integrated into a program cannot be determined.

It has been suggested that hydrotherapy for the reduction of lymphoedema volume is best undertaken in a pool temperature of $28^{\circ} \mathrm{C} .21$ Interestingly, two studies that were undertaken at temperatures closer to thermo-neutral $\left(33.5^{\circ} \mathrm{C}-34.5^{\circ} \mathrm{C}\right)$ had positive results in lymphoedema volume. ${ }^{22}$ Therefore, temperature may not be a primary consideration but rather the exercise program design that may hold greater importance. Compression therapy is considered the gold standard treatment for lymphoedema and has been proven effective in reducing lymphoedema volume. ${ }^{23}$ Despite the strong evidence for compression therapy, there was no obvious correlation between the beneficial effects of wearing compression garments in addition to hydrotherapy alone. It is possible that there was no additional benefit due to the hydrostatic properties of water. ${ }^{7}$ Additionally, Yeung and Semciw identified in their review, that adherence may have been a critical factor in compression garments not providing any benefit. ${ }^{10}$

\section{Duration/Frequency}

A previous study on land-based management in a BCRL population found that nine supervised sessions over a twelve week period was sufficient for an improvement in upper limb function. ${ }^{20}$ Although upper limb function is only one outcome in the multidimensional management of BCRL with hydrotherapy, all studies included in this review were inclusive of or exceeded nine treatment sessions over an eight to twelve week period. This suggests that in terms of overall duration, eight to twelve weeks may be a sufficient amount of time to yield improvements in some of the outcomes of interest. However, no recommendation regarding frequency can be made due to inconsistency in the total number of sessions within the studies. Furthermore, there appears to be no benefit in an increased frequency in the number of sessions resulting in more beneficial outcomes, as changes were found across the domains irrespective of frequency. The time period of the individual hydrotherapy sessions varied across the five studies, ranging from 20 to 60 minutes, with one study increasing the length of the hydrotherapy sessions progressively throughout the course of the program. ${ }^{17}$

\section{Method of Delivery}

Research indicates that factors affecting QOL such as self-confidence, self-esteem, motivation, and optimism improve in women with BCRL when participating in group therapy exercise classes. ${ }^{24}$ Two of the studies included in this review, which conducted

(C) The Internet Journal of Allied Health Sciences and Practice, 2017 
group based sessions, demonstrated an improvement in QOL.6,8 This finding is similar to that of Woo et al. who suggest that social and emotional well-being may be enhanced in a group treatment setting due to shared experiences. ${ }^{25}$

Physiotherapist supervision is an important factor associated with method of delivery as physiotherapist led exercises programs have been correlated with improved outcomes when compared with unsupervised exercise interventions. ${ }^{26,27}$ Four of the five included studies had physiotherapist supervision, one of which was only partially supervised.6,8,15-171 However, the partially or unsupervised interventions did not appear to have differing outcomes to supervised sessions. The findings from this review seem to be contradictory to findings from the literature on the benefits of supervision of exercise interventions. One explanation for this might be due to provision of clear, comprehensive session programs. Although there was no difference in outcomes, specialised programs such as ALT may benefit from initial supervision to ensure the key principles are adhered to. There were no adverse outcomes across the studies; therefore, hydrotherapy was found to be a safe intervention to complete with or without supervision.

\section{Limitations:}

As with any research, this systematic review has limitations. Despite the inclusion of several RCTs, some were pilot studies with numerous methodological limitations (small sample size, dissimilarity at baseline). All studies had small sample sizes except for the CCT conducted by Lindquist et al., which included 88 participants. ${ }^{15}$ Only one study that conducted power calculations met the required participant numbers. ${ }^{6}$ Consequently, a clinically meaningful effect cannot be determined for the remaining studies.

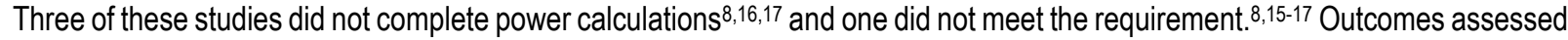
in all studies were only monitored immediately post-intervention and at the conclusion of the study, with the longest follow up at 12 weeks. Consequently, the long-term effect of the interventions cannot be commented on. Additionally, any effects that were identified immediately post-intervention were not followed up at a later time; thus, the lasting effect is unknown. The primary outcome of lymphoedema volume was represented in all studies. Pain, which was also identified as a primary outcome, was only included in one study. ${ }^{8}$ Pain has been identified as one of the most common symptoms associated with BCRL. It has been reported that pain has a large influence on secondary psychosocial and functional outcomes. ${ }^{3}$ Consequently, it is a limitation of the current evidence that pain is not a principle consideration. The secondary outcomes of $\mathrm{QOL}$ and upper limb function were present in two and three studies respectively. These outcomes were included to determine the effect hydrotherapy has from both physiological and holistic perspectives. Consequently, a complete representation of the effect of hydrotherapy as an adjunct treatment to usual care in secondary upper limb BCRL cannot truly be determined.

A requirement of this intervention is affordable and regular access to an appropriate hydrotherapy pool. While this may be accessible in some settings (such as metropolitan areas), barriers to access may exist in other settings (such as rural and remote). Supervision, pool memberships, and program costs may be additional factors that affect service delivery and are potential barriers to consider. Despite a comprehensive search strategy, potential for language bias should be acknowledged as only English language articles were included in this systematic review.

\section{CONCLUSIONS \\ Implications for Clinical Practice}

There is mixed evidence to support the use of hydrotherapy as an adjunct treatment to usual care in BCRL. Although the evidence base is limited, this recommendation is derived from studies of moderate methodological quality, of which four of the five included studies were RCTs. Hydrotherapy programs which incorporate slow rhythmical movements, deep breathing, and massage as an adjunct treatment may result in positive outcomes for lymphoedema volume in the short term. Furthermore, there is emerging evidence to indicate that shoulder strengthening and ROM exercises could be an essential component for improving upper limb function. From a psychosocial perspective, hydrotherapy in a group-based setting may be an important consideration in the management of BCRL, with this resulting in greater improvements in QOL. Given the issues with regards to availability of and access to a hydrotherapy pool, factors such as financial costs and patient preferences should be considered when recommending this as a co-intervention for BCRL.

\section{Implications for Further Research}

Given the heterogeneity of the intervention parameters, it is difficult to ascertain the most effective program type, frequency, intensity and duration. This diversity also results in varied treatment effects which makes comparisons difficult. Therefore, future research would benefit from studies that focus on developing standardised intervention parameters. Similarly, for the same reasons, future research should also focus on the development of standardised outcome measures for BCRL. Finally,

(C) The Internet Journal of Allied Health Sciences and Practice, 2017 
methodologically sound RCTs that are conducted with larger sample sizes and include long term follow-up that exceeds the length of the intervention would assist in identifying the sustained impact of hydrotherapy for BCRL.

\section{REFERENCES:}

1. Breast Cancer. Australian Government Web Site. Available at: https://canceraustralia.gov.au/affected-cancer/cancertypes/breast-cancer. Updated February 1, 2017. Accessed 28 February, 2017.

2. Australian Institute of Health and Welfare. Breast Cancer in Australia: An Overview. Australian Government. October 2012. Available at: http://www.aihw.gov.au/WorkArea/DownloadAsset.aspx?id=10737423006. Accessed February 27, 2017.

3. Keilani M, Hasenoehler T, Neubauer M, Crevanna R. Resistance exercise and secondary lymphedema in breast cancer survivors - a systematic review. Support Care Cancer. 2016;24(4):1907-16. [PMID: 26715294]

4. Devoogdt N, Kampen D, Geraerts I, Coremans T, Christiaens M. Different physical treatment modalities for lymphoedema developing after axillary lymph node dissection for breast cancer: A review. Eur J Obstet Gynecol Reprod Biol. 2010;149(1):3-9.[PMID: 20018422]

5. DiSipio T, Rye S, Newman B, Hayes $S$. Incidence of unilateral arm lymphoedema after breast cancer: a systematic review. Lancet Oncol. 2013;14(6):500-1. [PMID: 23540561]

6. Tidhar $\mathrm{D}$, Katz-Leurer M. Aqua lymphatic therapy in women who suffer from breast cancer treatment-related lymphedema: a randomized controlled study. Support Care Cancer. 2010;18(1):383-92. [PMID: 19495810]

7. Moovemthan A, Nibethithia L. Scientific Evidence Based Effects of Hydrotherapy on Various Systems of the Body. N Am J Med Sci. 2014;6(5):199-209. [PMID: 24926444]

8. Letellier M, Towers A, Shimony A, Tidhar D. Breast cancer-related lymphedema: a randomized controlled pilot and feasibility study. Am J Phys Med Rehabil. 2014;9(1)751-9. [PMID: 24743455]

9. Tidhar D, Shimony A. Drouin J. Aqua Lymphatic Therapy for Postsurgical Breast Cancer Lymphedema. Rehabilitation Oncology. 2004;22(3):6-14.

10. Yeung W, Semciw A. Aquatic Therapy for People with Lymphedema: A Systematic Review and Meta-analysis. Lymphat Res Biol. 2017:1-11. Epub 2017 Mar 27. [PMID: 28346851]

11. Hillier S, Grimmer-Somers K, Merlin T, Middleton O, Salisbury J, et al. FORM: An Australian method for formulating and grading recommendations in evidence-based clinical guidelines. BMC Med Res Methodol. 2011;11:23. [PMID: 21356039]

12. Shamseer L, Moher D, Clarke M, Ghersi D, Liberati A, et al. Preferred reporting items for systematic review and metaanalysis protocols (PRISMA-P) 2015: elaboration and explanation. BMJ. 2015;349:g7647. [PMID: 25555855]

13. Critical Appraisal Skills Programme (CASP). Randomised Controlled Trials Checklist. CASP UK. May 31, 2013. Available at: http://docs.wixstatic.com/ugd/dded87_40b9ff0bf53840478331915a8ed8b2fb.pdf. Accessed March 30, 2017.

14. National Health and Medical Research Council. NHMRC additional levels of evidence and grades for recommendations for developers of guidelines. Australian Government. 2009. Available at: https://www.nhmrc.gov.au/_files_nhmrc/file/guidelines/developers/nhmrc_levels_grades_evidence_120423.pdf. Accessed February 29, 2017.

15. Lindquist H, Emblom A, Dunberger G, Nyberg T, Bergmark K. Water exercise compared to land exercise or standard care in female cancer survivors with secondary lymphedema. Lymphology. 2015;48(1):64-79. [PMID: 26714371]

16. Johannson K, Hayes S, Speck R, Schmitz K. Water-Based Exercises for Patients with Chronic Arm Lymphedema: A Randomized Controlled Pilot Trial. Am J Phys Med Rehabil. 2013;92(3):312-9. [PMID: 23370582]

17. Hayes $\mathrm{S}$, Reul-hirche $\mathrm{H}$, Turner $\mathrm{J}$. Exercise and secondary lymphedema: safety potential benefits, and research issues. Med Sci Sports Exerc. 2009;41(3):483-9. [PMID: 19204604]

18. Newman A. A comparison of three intervention methods for women with breast cancer-related lymphedema: a pilot study [thesis]. Montreal, Quebec, Canada: Concordia University; 2013.

19. Williams A. Manual lymphatic drainage: exploring the history and evidence base. Br J Community Nurs. 2010;15(4):18-24. [PMID: 20559172]

20. Beursken C, van Uden C, Strobbe L, Oostendorp RA, Wobbes T. The efficacy of physiotherapy upon shoulder function following axillary dissection in breast cancer, a randomized controlled study. BMC Cancer. 2007;7:166-72. [PMID: 17760981]

21. Moseley A, Carati C, Piller N. A systematic review of common conservative therapies for arm lymphedema secondary to breast cancer treatment. Ann Oncol. 2007;18(4):639-46. [PMID: 17018707]

22. Aquatic Physiotherapy Group. Australian Guidelines for Aquatic Physiotherapists Working in and/or Managing Hydrotherapy Pools. Australian Physiotherapy Association 2015. Available at: 
http://www.physiotherapy.asn.au/DocumentsFolder/APAWCM/The\%20APA/National\%20Groups/Aquatic\%20Physiothera py\%20-\%20Guidelines.pdf. Accessed May 30, 2017.

23. Moffatt C, Doherty D, Morgan P. Best practice for the management of lymphedema. Lymphoedema Framework. 2006. Available at: http://www.woundsinternational.com/media/issues/210/files/content_175.pdf. Accessed May 30, 2017.

24. Bracha J, Jacob T. Using exercise classes to reduce arm lymphoedema. J Lymphoedema. 2010;5(1):46-55.

25. Woo J, Chan W, Yeung F. A community model of group therapy for the older patients with chronic obstructive pulmonary disease: a pilot study. J Eval Clin Pract. 2006;12:523-31. [PMID: 16987114]

26. Deyle GD, Allison SC, Matekel RL, Ryder MG, Stang JM, et al. Physical therapy treatment effectiveness for osteoarthritis of the knee: a randomized comparison of supervised clinical exercise and manual therapy procedures versus a home exercise program. Phys Ther. 2005;85(12):1301-17. [PMID: 16305269]

27. Mutrie N, Campbell A, Whyte F, McConnachie A, Emslie C, et al. Benefits of supervised group exercise programme for women being treated for early stage breast cancer: pragmatic randomized controlled trial. BMJ. 2007;334(7592):517. [PMID: 17307761] 